\title{
Current and emerging therapies for the treatment of osteoporosis
}

\author{
This article was published in the following Dove Press journal: \\ Journal of Experimental Pharmacology \\ 27 August 2010 \\ Number of times this article has been viewed
}

\section{Jill Waalen}

Department of Molecular and Experimental Medicine, The Scripps Research Institute, CA, USA
Correspondence: Jill Waalen

Department of Molecular and Experimental Medicine, The Scripps Research Institute, 10550 North Torrey

Pines Road, La Jolla, CA 92037, USA

$\mathrm{Tel}+\mathrm{I} 8587848042$

Fax +I 8587842083

Email jwaalen@scripps.edu
Abstract: Osteoporosis represents a weakening of bone tissue due to an imbalance in the dynamic processes of bone formation and bone resorption that are continually ongoing within bone tissue. Most currently available osteoporosis therapies are antiresorptive agents. Over the past decade, bisphosphonates, notably alendronate and risedronate, have become the dominant agents with newer bisphosphonates such as ibandronate and zoledronic acid following a trend of less frequent dosing regimens. Synthetic estrogen receptor modulators (SERMs) continue to be developed as drugs that maintain the bone-protective effects of estrogen while avoiding its associated adverse side effects. Currently available agents of this class include raloxifene, the only SERM available in the United States (US), and lasofoxifene and bazedoxifene, available in Europe. Calcitonin, usually administered as a nasal spray, completes the list of currently approved antiresorptive agents, while parathyroid hormone analogs represent the only anabolic agents currently approved in both the US and Europe. Strontium ranelate is an additional agent available in Europe but not the US that has both anabolic and antiresorptive activity. New agents expected to further expand therapeutic options include denosumab, a monoclonal antibody inhibitor of the resorptive enzyme cathepsin K, which is in the final stages of Food and Drug Administration approval. Other agents in preclinical development include those targeting specific molecules of the $\mathrm{Wnt} / \mathrm{\beta}$-catenin pathway involved in stimulating bone formation by osteoblast cells. This review discusses the use of currently available agents as well as highlighting emerging agents expected to bring significant changes to the approach to osteoporosis therapy in the near future.

Keywords: bone formation, bone resorption, antiresorptive agent, anabolic agent

\section{Introduction}

Bone is a dynamic tissue, undergoing a continual remodeling process involving a cycle of formation of new bone tissue and breakdown (resorption) of older bone tissue. In osteoporosis, the balance of these processes is tipped toward resorption, leading to weakening of bone tissue and increased risk of fracture. Pharmacotherapy for the prevention and treatment of osteoporosis has predominantly been based on agents that prevent resorption of bone. Most available agents are effective at increasing bone mineral density or preventing fractures of the vertebra. The majority also have effects on nonvertebral sites, including the hip.

Over the past decade, bisphosphonates have become the most commonly prescribed osteoporosis medication following the decline of the use of estrogen-based hormone therapy as a result of the United States (US) Women's Health Initiative trial. Focus in hormone therapy has shifted to synthetic estrogen receptor modulators (SERMs) 
designed to retain the positive effects of estrogen on bone while minimizing the negative effects of increasing risk of cardiovascular disease and cancer. Calcitonin hormone (another antiresorptive agent), parathyroid hormone (PTH) analogs (to date the only anabolic agent for osteoporosis treatment available in the US), and strontium ranelate (an agent with both anabolic and antiresorptive activity used widely in Europe, but not the US) complete the list of currently available treatment options.

New treatments in clinical trials include both new generations of currently available therapies and agents with novel mechanisms of action. New therapeutic strategies are also emerging from recent discoveries regarding the role of biologic pathways such as the Wnt/ $\beta$-catenin pathway in regulating bone cell function. These strategies include more agents targeted to promote bone growth with the potential to be more effective in preventing fractures than current approaches.

\section{Disease prevalence and treatment guidelines}

Osteoporosis represents a condition of compromised bone strength predisposing a person to an increased risk of fracture. Bone strength depends on both bone quality and bone density. While bone density is relatively easily measured, by dual $\mathrm{x}$-ray absorptiometry (DXA) and other modalities, there are few good measures of bone quality. Bone mineral density (BMD) has thus become the most common clinical measure of osteoporosis, although its relationship to risk of fracture is not strictly proportional. ${ }^{1,2}$

The World Health Organization (WHO) has defined osteoporosis as a BMD measurement of 2.5 standard deviations or more below the population mean BMD of sex-matched young adults, ie, a T-score of $\leq-2.5 .{ }^{3} \mathrm{BMD}$ is typically measured at the lumbar spine, femoral neck, and hip. A T-score of $<-2.5$ at any of those sites is diagnostic for osteoporosis. Osteopenia, or low bone mass, is defined as 1.5 to 2.5 standard deviations below the population mean. The occurrence of a nontraumatic fracture, regardless of BMD, is also considered by definition to be osteoporosis.

According to statistics compiled by the International Osteoporosis Foundation, more than 75 million people in the United States, Europe, and Japan have osteoporosis with an additional 70 million persons likely affected in China. ${ }^{4}$ The US National Osteoporosis Foundation (NOF) has estimated that 10 million people have osteoporosis in the US alone with another 34 million having osteopenia. ${ }^{5}$ As a result, lifetime risk of fracture for whites over the age of 50 years in the US is estimated to be $53 \%$ for females and $21 \%$ for males. ${ }^{5}$ Fractures are costly to the individual in terms of morbidity - leading to chronic pain, disability, and loss of independence - and increased mortality. Costs to society are also high; according to NOF, two million osteoporotic fractures occur in the US per year, costing \$19 billion/ year in treatment costs. ${ }^{5}$ By the year 2015, these numbers are expected to increase to three million fractures at a cost of more than $\$ 25$ billion/year. Nine million osteoporotic fractures are estimated to occur annually worldwide. ${ }^{4}$

An international consensus regarding who to screen and treat does not currently exist. ${ }^{6}$ In the US, BMD screening is recommended by most organizations for all women aged 65 years and older, all men aged 70 years and older, and women and men aged 50 to 70 at high risk for the disease. ${ }^{7}$ Risk calculators, such as WHO's online FRAX ${ }^{\circledR}$ calculators (World Health Organization Collaborating Centre for Metabolic Bone Diseases, University of Sheffield, UK) can determine an individual's specific risk of fracture over the next 10 years based on country of residence and by inputting femoral neck BMD along with age, sex, height, weight, history of personal or parental fracture, smoking and drinking status, history of rheumatoid arthritis, use of glucocorticoids, or secondary osteoporosis. ${ }^{8}$

Guidelines from NOF and other organizations in the US call for initiation of treatment in the following patients: ${ }^{9}$

1. Patients with hip or vertebral fractures

2. Patients with BMD T-scores $\leq-2.5$ at the femoral neck, total hip, or spine by DXA

3. Postmenopausal women or men $\geq 50$ years old with low bone mass (T-score between -1 and -2.5 ) at the femoral neck, total hip, or spine AND:

a. 10 year hip fracture probability $\geq 3 \%$ OR

b. 10 year all major osteoporosis-related fracture probability of $\geq 20 \%$ based on the US-adapted WHO absolute fracture risk model

Osteoporosis is largely under-treated. In one study in the US, it was shown that only $26 \%$ of white women at high risk for fracture were receiving osteoporosis therapy, with the rate being less than 3\% among men and black women with the same risk. ${ }^{1}$ Low rates of adherence to osteoporosis medications contribute to under-treatment of the disease, with most studies estimating that $50 \%$ or less of patients with a prescription for osteoporosis medication actually take the medication as prescribed, regardless of the type of medication or frequency of dosing. ${ }^{10}$ Improved adherence thus continues to be a goal in osteoporosis therapy. 


\section{Bone biology}

Pharmacologic therapies for osteoporosis have been targeted to a number of different molecular processes involved in the bone remodeling cycle. Bone tissue is specialized connective tissue composed of cells, organic bone matrix, and inorganic calcified crystals. In addition to its mechanical function, bone plays a role in metabolic functions, such as serving as the primary storage site for calcium, phosphate, and other minerals. Thus, bone remodeling is not only altered by mechanical stresses, but also responds to a number of systemic hormones that regulate calcium homeostasis.

There are three primary cell types in bone, two of which, osteoblasts and osteoclasts, are located at the surface of the bone matrix. Osteocytes, which are derived from osteoblasts, are embedded in the bone matrix (Figure 1). During the continual bone remodeling cycle, osteoclasts demineralize and resorb old bone, and osteoblasts deposit new bone to maintain a bone mass that adequately responds to the stresses placed on the skeleton.

Osteoblasts actively produce osteoid, the organic component of the bone matrix, composed mainly of Type I collagen fibers along with a mixture of proteoglycans, phosphoproteins, phospholipids, hyaluronic acid, and glycoproteins (Figure 1). ${ }^{11,12}$ Two of these glycoproteins, osteocalcin and sialoprotein, are bone-specific and have a high affinity for calcium. The inorganic component of the bone matrix is made up of calcium and phosphorus deposited along the osteoid scaffolding primarily in the form of hydroxyapatite crystals. Osteoclasts resorb the matrix by secreting hydrochloric acid, which dissolves calcium phosphate, and enzymes such as collagenases and other proteases. The most important of the proteases is cathepsin $\mathrm{K}$, which degrades the organic matrix including Type I collagen. ${ }^{11}$

Normally the processes of bone formation and bone resorption are tightly balanced. Disturbance of this balance can compromise bone density, strength, and microarchitecture. Most often this occurs due to increased osteoclast activity, leading to increased bone resorption and diminished bone density. In post-menopausal women, increased osteoclast activity results from the loss of estrogen; with the largest decrease in BMD occurring within five years of the beginning of menopause. ${ }^{13}$

Systemic calcium homeostasis is under the control of three hormones with direct effects on bone tissue: vitamin $\mathrm{D}$, calcitonin, and PTH. Activated vitamin D3 stimulates intestinal absorption of calcium. In bone, vitamin D3 binds to receptors on osteoblasts to increase release of osteocalcin and another glycoprotein, osteopontin, to facilitate mineralization. ${ }^{14} \mathrm{PTH}$ is released from the

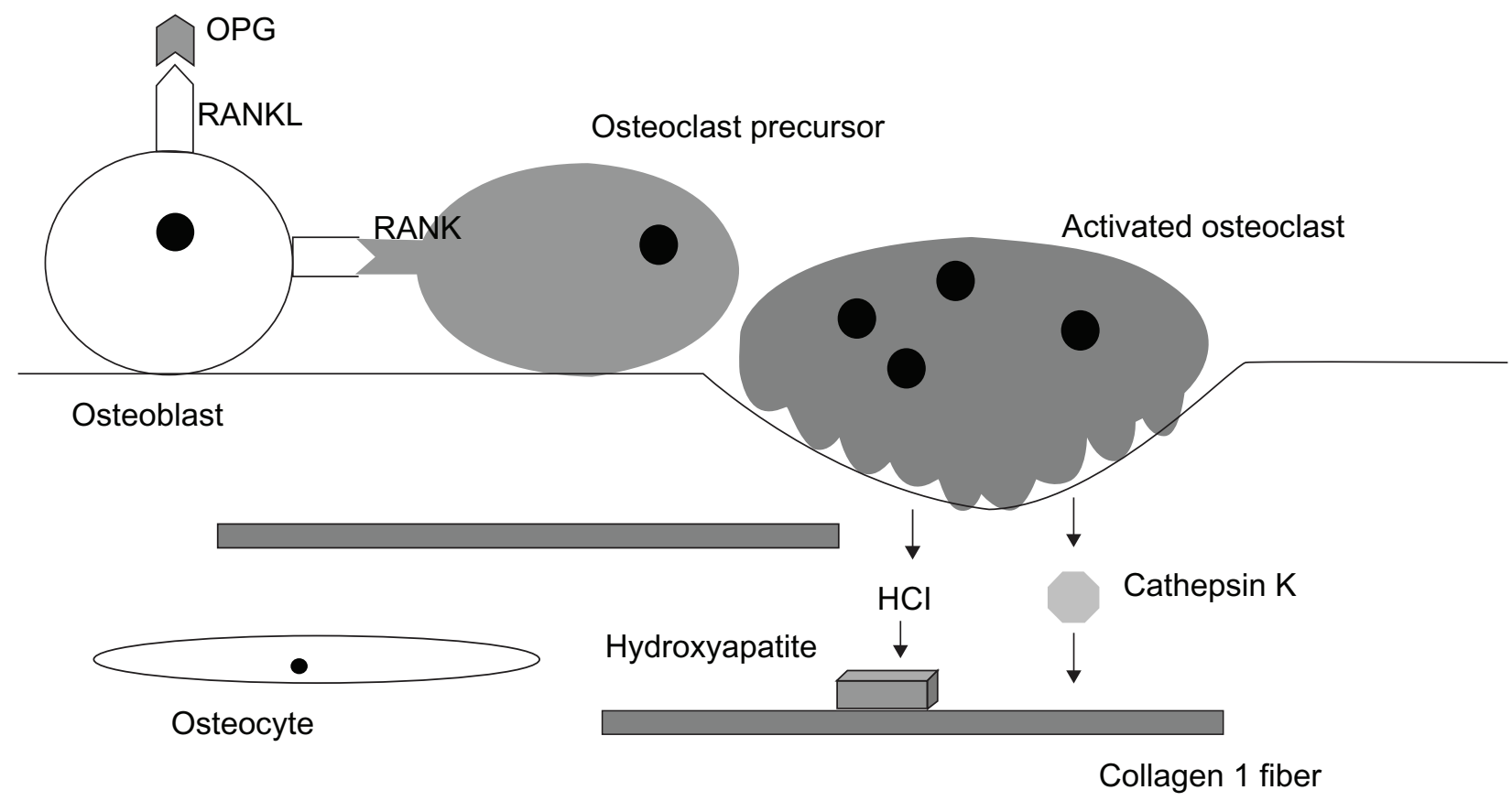

Figure I RANK/RANKL/Osteoprotegerin signaling system in bone. Osteoblasts express the membrane-bound signaling protein receptor activator of NF kappa B ligand (RANKL) that binds to its receptor (RANK) on osteoclast precursor cells to stimulate their differentiation into activated multinucleated osteoclasts. Osteoprotegerin (OPG) secreted by local cells including osteoblasts also binds RANK and inhibits this activation. Activated osteoclasts secrete proteinases, including the collagenase cathepsin K that degrades collagen I fibers, the major organic component of bone matrix. The osteoclasts also secrete hydrochloric acid that dissolves the calcium phosphate hydroxyappatite crystals of the matrix. 
parathyroid glands in response to low calcium. Continuous high PTH levels act to mobilize calcium and phosphorus by stimulating resorption by osteoclasts. ${ }^{15}$ High serum calcium feeds back to inhibit PTH release. Calcitonin is released from the thyroid gland in response to high serum calcium levels. It binds to receptors on osteoclasts and directly inhibits their activity, leading to reduced resorption and lower calcium levels. ${ }^{15}$

Estrogen is another systemic hormone with direct effects on bone and playing an important role in osteoporosis. Recently it has been shown that estrogen acts through the estrogen receptor $\alpha(E R \alpha)$ on osteoclasts to facilitate the expression of the FasL gene and induce apoptosis of osteoclasts, thereby controlling their lifespan. ${ }^{16,17}$

Within bone tissue, resorption is controlled by a system of three key proteins: RANK (receptor activator of nuclear factor kappa beta), its ligand RANKL (receptor-activator of nuclear factor kappa beta ligand), and a decoy receptor OPG (osteoprotegerin) (Figure 1). ${ }^{18}$ Binding of RANKL, a membrane-bound protein produced by osteoblasts, to RANK, the receptor on osteoclasts, leads to increased osteoclast differentiation, activation, and survival, resulting in increased bone resorption. OPG acts as a decoy receptor by binding with high affinity to RANKL therefore preventing the interaction with RANK. OPG thus acts as an effective inhibitor of bone resorption.

Many of the products of these processes can be measured as biochemical markers of bone turnover. Markers in current clinical use include, but are not limited to, degradation products of collagen I breakdown: telopeptides of the N-terminal (urinary NTx) and C-terminal (serum CTx) of collagen type 1; early markers of bone formation: N-terminal, propeptide of type 1 collagen and bone-specific alkaline phosphatase; and osteocalcin, a late marker of bone formation that appears only in the mineralization phase. ${ }^{19}$ Cathepsin $\mathrm{K}$ is also considered a marker of bone turnover.

In contrast to imaging techniques, biochemical markers of bone turnover obtained in serum samples show changes in a markedly larger range. Typically a decrease of $50 \%-80 \%$ or an increase of $100 \%-200 \%$ occurs in days or weeks of initiating treatment with antiresorptive or anabolic drugs compared with usual increases in BMD of $6 \%-7 \%$ with bisphosphonates and $2 \%-3 \%$ with SERMs after two years of therapy. ${ }^{19}$

\section{Current pharmacologic treatments}

Pharmacologic therapies for osteoporosis are all recommended in the context of standard nonpharmacologic therapy including adequate calcium, vitamin $\mathrm{D}$, and weight-bearing exercise. Calcium supplements are recommended for adults at doses of $1,000 \mathrm{mg}$ daily until age 50 and $1,200 \mathrm{mg}$ /day for adults over age 50 years..$^{20}$ Concurrent vitamin D supplementation to ensure adequate calcium absorption is also recommended at doses of 800-1,000 international units (IU)/day for adults ages 50 and older, with the goal of achieving serum levels of at least $30 \mathrm{ng} / \mathrm{mL}$. Assessment of vitamin D status is important, given that an estimated $77 \%$ of adults in the US are considered to have inadequate levels of vitamin D, ie, below $30 \mathrm{ng} / \mathrm{mL} .{ }^{21}$ Sunlight exposure is important in maintaining adequate levels of vitamin $\mathrm{D}$, causing production of the vitamin $\mathrm{D}_{3}$ prohormone through ultraviolet $\mathrm{B}$ irradiation of its 7-dehydrocholesterol precursor in the skin. ${ }^{22}$ However, even in latitudes where the sunlight intensity can facilitate this reaction year-round, insufficient levels of vitamin D are common in the population. ${ }^{23}$ Although no formal recommendations for amounts of sun exposure exist, research referenced by the US National Institutes of Health has suggested that 5-30 minutes of exposure between $10 \mathrm{am}$ and $3 \mathrm{pm}$ at least two times a week without sunscreen may be adequate to maintain vitamin D levels. ${ }^{24}$ For patients who are vitamin D-deficient, replacement levels of oral vitamin D of 50,000 IU/week should be taken for 8-12 weeks and then at least $1,000 \mathrm{IU} /$ day. ${ }^{25}$

Exercise, including weight-bearing activities such as running, jumping, and resistance training, can also contribute to osteoporosis prevention. Specific recommendations for maintenance of bone health from organizations such as the US NOF and the American College of Sports Medicine include performance of weight-bearing exercise for a total of 30 minutes on most days and resistance training of 8-12 repetitions or $8-10$ exercises at least two days a week..$^{26,27}$ Common-sense fall prevention strategies also contribute to fracture prevention.

An osteoporosis medication may have an indication for prevention of osteoporosis in patients with low bone mass, treatment of patients with already established osteoporosis, or both (Table 1). To be approved for prevention of osteoporosis in patients in the US, agents must be shown in clinical trials to significantly increase BMD in patients with low bone mass. Therapies approved for treatment of already established osteoporosis must demonstrate a significant reduction in fractures.

Most currently approved drugs for osteoporosis prevention or treatment are antiresorptive (Table 1). The bisphosphonates, alendronate and risedronate, are often the first drugs recommended for treating postmenopausal osteoporosis. Bisphosphonates are approved for both 
Table I Osteoporosis therapies currently approved in the US

\begin{tabular}{|c|c|c|c|c|c|c|c|c|c|}
\hline Drug & Prevention & Treatment & Spine & Hip & $\begin{array}{l}\text { Other } \\
\text { nonvertebral }\end{array}$ & Oral & Intravenous & Subcutaneous & $\begin{array}{l}\text { Nasal } \\
\text { spray }\end{array}$ \\
\hline \multicolumn{10}{|c|}{ BISPHOSPHONATES } \\
\hline \multirow[t]{2}{*}{ Alendronate } & $\mathrm{X}$ & $x$ & $\mathrm{x}$ & $\mathrm{x}$ & $x$ & $5-10 \mathrm{mg}$ daily & & & \\
\hline & & & & & & 35-70 mg weekly & & & \\
\hline \multirow[t]{3}{*}{ Risedronate } & $x$ & $x$ & $x$ & $x$ & $x$ & $5 \mathrm{mg}$ daily & & & \\
\hline & & & & & & $35 \mathrm{mg}$ weekly & & & \\
\hline & & & & & & I50 mg monthly & & & \\
\hline \multirow[t]{2}{*}{ Ibandronate } & $x$ & $x$ & $x$ & & & $2.5 \mathrm{mg}$ daily & $3 \mathrm{mg}$ every & & \\
\hline & & & & & & I50 mg monthly & 3 months & & \\
\hline \multirow[t]{2}{*}{ Zoledronic acid } & $x$ & $x$ & $x$ & $x$ & $x$ & & $5 \mathrm{mg}$ once & & \\
\hline & & & & & & & a year & & \\
\hline \multicolumn{10}{|l|}{ ESTROGEN } \\
\hline Conjugated & $x$ & & $x$ & $x$ & $x$ & Lowest possible & & & \\
\hline equine estrogen & & & & & & dose, eg, $0.3 \mathrm{mg}$ & & & \\
\hline with or without & & & & & & CEE (plus $1.5 \mathrm{mg}$ & & & \\
\hline \multirow[t]{3}{*}{ progestin } & & & & & & medroxyprogest- & & & \\
\hline & & & & & & erone acetate) & & & \\
\hline & & & & & & daily to start & & & \\
\hline \multicolumn{10}{|l|}{ SYNTHETIC } \\
\hline \multicolumn{10}{|l|}{ ESTROGEN } \\
\hline \multicolumn{10}{|l|}{ RECEPTOR } \\
\hline \multicolumn{10}{|l|}{ MODULATORs } \\
\hline \multicolumn{10}{|l|}{ (SERMs): } \\
\hline Raloxifene & $x$ & $x$ & $x$ & & & $60 \mathrm{mg}$ daily & & & \\
\hline \multicolumn{10}{|l|}{ HORMONE } \\
\hline \multicolumn{10}{|l|}{ ANALOGS } \\
\hline Salmon & & $x$ & $x$ & & & & & 25-I00 IU daily & $200 \mathrm{IU}$ \\
\hline calcitonin & & & & & & & & & daily \\
\hline Parathyroid & & $x$ & & & & & & 20 ug daily & \\
\hline \multicolumn{10}{|l|}{ hormone } \\
\hline (teriparatide) & & & & & & & & & \\
\hline
\end{tabular}

prevention and treatment. Indications for estrogen are limited to prevention, whereas the calcitonin and PTH analogs are reserved for treatment. PTH is the single anabolic agent currently available in the US. Its use is limited to treatment of osteoporosis for two-year periods.

The focus of the therapies presented here is the treatment and prevention of primary osteoporosis associated with menopause and aging. However, it should be noted that a number of other diseases, as well as drugs and nutritional deficiencies, can cause secondary osteoporosis, the most frequent being glucocorticoid excess. Other conditions associated with secondary osteoporosis include endocrine disorders such as Cushing's syndrome, hypogonadism, and Type 1 diabetes mellitus; gastrointestinal disease including celiac disease and other malabsorption syndromes, and liver disorders; bone marrow-related conditions such as thalassemia and other anemias; and other miscellaneous causes including chronic obstructive pulmonary disease, multiple sclerosis, and rheumatoid arthritis. Among the numerous medications associated with osteoporosis are heparin, anticonvulsants such as phenytoin and phenobarbitol, lithium, cancer chemotherapeutic agents, and excessive thyroid hormone. ${ }^{28}$ Although patients with secondary osteoporosis can benefit from therapies used for primary osteoporosis, it is important to identify secondary osteoporosis because there are often effective specific interventions that can be added to the more general approach.

\section{Antiresorptive agents}

\section{Bisphosphonates}

Bisphosphonates are the most commonly prescribed drugs used to treat osteoporosis in the US and many other countries. Etidronate was the first bisphosphonate to be used as therapy beginning in the 1960s. Although its approved indications in the US are limited to treatment of hypercalcemia and Paget's disease, a disease of accelerated bone turnover, etidronate is commonly used in Europe and other countries for treatment of osteoporosis as cyclic oral therapy, given for two weeks every 
three months. ${ }^{29}$ Alendronate, a once daily oral medication, was the first bisphosphonate to be approved for treatment of osteoporosis in the US in 1995. Since that time, newer bisphosphonates with less frequent dosing intervals have been introduced, partially in an attempt to improve compliance. In addition to alendronate, three other bisphosphonates have been approved in the US for both treatment and prevention of osteoporosis. Risedronate is an oral medication that can be administered daily, weekly, or monthly at varying doses (Table 1). Zoledronic acid is medication administered once yearly by intravenous transfusion. Ibandronate is available in both oral and intravenous forms at various dosing frequencies.

Other bisphosphonates not approved in the US, but available in other countries for treatment of osteoporosis, include clodronate and pamidronate. Both are usually taken as oral agents, but are also available for intravenous, and in the case of clodronate, intramuscular administration. ${ }^{30}$

Bisphosphonates are structurally related to inorganic pyrophosphate, a naturally occurring compound composed of two phosphate groups. ${ }^{31}$ Like pyrophosphate, bisphosphonates bind to hydroxyapatite crystals and thus have a very high affinity for bone. Upon exposure to acid and enzymes secreted by an active osteoclast, bisphosphonates are released from the bone matrix where they promote osteoclast apoptosis. $^{31,32}$

Bisphosphonates differ in strength of binding to the bone mineral matrix, with the zoledronic acid having the highest affinity followed by pamidronate $>$ alendronate $>$ ibandronate $>$ risedronate $>$ etidronate $>$ clodronate..$^{31,33}$ Higher-affinity bisphosphonates bind avidly to the bone surface, but spread through bone slowly. Lower-affinity agents are distributed more widely through the bone, but have a shorter residence time when treatment is stopped. Suppression of bone resorption occurs within approximately three months of initiation of oral bisphosphonate therapy regardless of dosing frequency, but is more rapid after intravenous administration. Length of suppression is largely a function of affinity for mineral matrix binding; zoledronic acid, with the highest affinity, effectively suppresses markers of bone turnover for up to one year.

Bisphosphonates in general have been shown to increase BMD of the spine by $5 \%-8 \%$ and at the hip by $3 \%-6 \%$ after three years. All bisphosphonates have been shown to reduce vertebral fractures by $40 \%-70 \% .^{32}$ Aldenronate, risedronate, and zoledronic acid also reduced nonvertebral fractures by $25 \%-40 \%$, including hip fractures by $40 \%-60 \%$, in women with osteoporosis. ${ }^{32}$ Ibandronate has not been shown to reduce nonvertebral fractures.

Divalent cations from food or other ingested sources will completely block absorption of oral bisphosphonates. Therefore, these agents must be taken after a prolonged fast, followed by 30-60 minutes with nothing else by mouth. Even under these conditions, less than $1 \%$ of an orally administered dose is absorbed. Bisphosphonates do not undergo systemic metabolism and their plasma half-lives are short. Fifty percent of the absorbed dose binds to bone surfaces; the other $50 \%$ is excreted rapidly by the kidneys. ${ }^{32}$

Because bisphosphonates accumulate in bone, they can be continued to be released from bone for months or years after treatment is stopped and may protect against fracture for 3-5 years after treatment is stopped. ${ }^{32}$ On this basis, consideration of a "drug holiday" after 5-10 years of bisphosphonate treatment has been advocated, with longer treatment periods and shorter off-treatment periods recommended for those at greatest risk of fracture.

Side effects of bisphosphonates include upper gastrointestinal symptoms and infrequent bone, joint, and/or muscle pain. Osteonecrosis of the jaw is another rare, but serious, side effect that was identified through post-marketing surveillance. According to a report of a task force of the American Society for Bone and Mineral Research, osteonecrosis of the jaw, formally defined as the presence of exposed bone in the maxillofacial region that does not heal within eight weeks of identification by a healthcare provider, was estimated to occur in between one in 10,000 to less than one in 100,000 patient years. ${ }^{34} \mathrm{~A}$ recent re-evaluation of three large, randomized controlled trials of bisphosphonates has shown no increase in "atypical" femoral shaft fractures, which had previously been suggested to be linked to their use. ${ }^{35}$

\section{Estrogen}

Estrogen has long been used in the prevention of osteoporosis, with widespread use beginning in the 1980s when it was cited by a US National Institutes of Health Consensus Conference as the most effective means for preventing bone loss. ${ }^{36}$ Use of conjugated equine estrogen (CEE) in combination with progestins, to protect against adverse endometrial changes, continued to increase through the 1990s, so that by 2001 approximately 15 million women in the US aged 50-74 years were using estrogen therapy, with $42 \%$ of women of that age estimated to have had some exposure to hormone replacement therapy. ${ }^{37}$ 
Following release of results of the Women's Health Initiative (WHI) in 2002 showing increased adverse events associated with estrogen therapy, its use declined rapidly worldwide. ${ }^{38-42}$ Although confirming the association of estrogen with decreases in biochemical markers of osteoporosis of $50 \%-60 \%$, a two-year increase in BMD of $4 \%-6 \%$ in the hip and spine, and decreased incidence of both vertebral and hip fractures of $34 \%$ after five years, the trial was stopped three years early due to significantly increased risks of coronary heart disease, stroke, pulmonary embolism, and breast cancer in estrogen/progestin users compared with the placebo group..$^{43} \mathrm{~A}$ year and a half later, the estrogen-only arm in post-menopausal women with hysterectomy was also stopped early due to increased incidence of stroke. ${ }^{44}$

Estrogen therapy is now recommended for osteoporosis prevention only in patients with significant risk of osteoporosis and only after all nonestrogen medication has been carefully considered. The recommended starting dose is $0.3 \mathrm{mg}$ CEE (plus $1.5 \mathrm{mg}$ medroxyprogesterone acetate). Currently no estrogen (or progestin) product has a Food and Drug Administration (FDA) indication for treatment of osteoporosis. ${ }^{45}$

\section{SERMs}

SERMs represent a growing number of compounds that act as either estrogen receptor agonists or antagonists in a tissue-specific manner. They are a chemically diverse group that lack the steroid structure of estrogen, but possess a tertiary structure that allows them to bind to estrogen receptors ER-alpha and/or ER-beta. The goal is to develop SERMs that dissociate the favorable estrogenic effects on bone and the cardiovascular system from unfavorable stimulatory effects associated with breast and endometrial cancer.

Currently there are two main chemical classes of SERMs approved for clinical use: triphenyl ethylene derivatives (tamoxifen and toremifene which are used to treat breast cancer) and benzothiopene derivatives (such as raloxifene, the only SERM currently indicated for the prevention and treatment of osteoporosis in the US). In 2007, raloxifene was also granted an indication for breast cancer prevention by the FDA.

Raloxifene is an oral medication given in a dose of $60 \mathrm{mg} /$ day. Four major international trials have assessed the use of raloxifene in 37,000 postmenopausal women. ${ }^{46}$ In two osteoporosis prevention trials ${ }^{47,48}$ and two treatment trials of women with postmenopausal osteoporosis, ${ }^{49,50}$ raloxifene use has been associated with a $30 \%$ reduction in biochemical markers of osteoporosis, three-year increases in BMD of $2 \%$ and $3 \%$ at the hip and spine and decreased vertebral fractures by $30 \%-50 \%$ in women with pre-existing vertebral fractures or low bone density. It has not been shown to have a significant effect on nonvertebral or hip fractures. Raloxifene is associated with hormonally related side effects such as increased risk of blood clots and vasomotor symptoms, including hot flushes.

Two newer SERMs that have recently received approval in Europe, but are not yet approved in the US, are lasofoxifene and bazedoxifene (Table 2). Lasofoxifene is a third generation naphthalene derivative SERM that binds to both ER $\alpha$ and ER $\beta$ with high affinity. Its half-life is two times longer than that of raloxifene and it has better oral bioavailability. ${ }^{51}$ Lasofoxifene has been tested in 17 Phase II/III trials involving more than 10,000 women for postmenopausal osteoporosis

Table 2 Osteoporosis therapies not currently approved in the US

\begin{tabular}{|c|c|c|c|c|}
\hline Drug & Effect & Mechanism of action & Dosing & Status \\
\hline $\begin{array}{l}\text { Strontium } \\
\text { ranelate }\end{array}$ & $\begin{array}{l}\text { Anabolic } \\
\text { and antiresorptive }\end{array}$ & $\begin{array}{l}\text { Calcium-like atom; stimulates } \\
\text { osteoblasts and inhibits } \\
\text { osteoclasts }\end{array}$ & Oral & $\begin{array}{l}\text { Approved in Europe since 2004; } \\
\text { Related compound, strontium } \\
\text { malonate, in clinical trials in US }\end{array}$ \\
\hline Odanacatib & Antiresorptive & Cathepsin $\mathrm{K}$ inhibitor & Oral & In Phase III trials in the US \\
\hline Ostabolin-C & Anabolic & $\begin{array}{l}\text { Parathyroid hormone analog; } \\
\text { stimulates osteoblasts via PTH } \\
\text { receptor-I }\end{array}$ & Subcutaneous & In Phase III trials in the US \\
\hline Lasofoxifene & Antiresorptive & SERM & Oral & $\begin{array}{l}\text { Approved in Europe since 2009; } \\
\text { in Phase III trials in the US }\end{array}$ \\
\hline Bazedoxifene & Antiresorptive & SERM & Oral & $\begin{array}{l}\text { Approved in Europe since 2009; } \\
\text { US approval pending additional } \\
\text { information as of April } 2010\end{array}$ \\
\hline Denosumab & Antiresorptive & $\begin{array}{l}\text { Anti-RANKL monoclonal } \\
\text { antibody }\end{array}$ & Subcutaneous & $\begin{array}{l}\text { Approval in US and Europe } \\
\text { expected in } 2010\end{array}$ \\
\hline
\end{tabular}


prevention or treatment, with key evidence coming from two large Phase III trials. ${ }^{52}$ In the Osteoporosis Prevention and Lipid Lowering study involving 1,907 women, increases in lumbar BMD of $2.3 \%$ were observed among those receiving lasofoxifene 0.25 or $0.5 \mathrm{mg} /$ day, compared with a $0.7 \%$ reduction in patients who received placebo. ${ }^{53}$ The Postmenopausal Evaluation and Risk Reduction with Lasofoxifene (PEARL) trial demonstrated a reduction in vertebral fractures of $42 \%$ after three years and nonvertebral fractures, primarily forearm and wrist, of $24 \%$ among women with osteoporosis after five years of treatment. ${ }^{54}$ Rates of venous thromboembolism were also significantly increased. Based on earlier data from the PEARL trial, an FDA application for lasofoxifene was submitted in September 2008. Approval is currently pending a response to a request for additional information. Lasofoxifene $0.5 \mathrm{mg} /$ day was approved for treatment of osteoporosis by the European FDA counterpart, the European Medicines Agency, in 2009 and is available as a prescription drug there.

Bazedoxifene is another third generation SERM currently undergoing investigation in clinical trials. It is based on a raloxifene template with an indole ring substituting for the benzothioprine core. ${ }^{55}$ In clinical trials of postmenopausal women with osteopenia, bazedoxifene $20 \mathrm{mg}$ /day and $40 \mathrm{mg}$ /day resulted in increases in BMD at the lumbar spine and other sites of approximately $1.5 \%$ and was associated with significant decreases in markers of bone turnover. ${ }^{56}$ In Phase III trials, bazedoxifene in doses of $20 \mathrm{mg} /$ day or $40 \mathrm{mg}$ /day was associated with reduction of vertebral fractures of $39 \%$ and a nonsignificant reduction of all fractures of $16 \%$ over three years. ${ }^{57}$ Among women at high risk of fracture in the next 10 years $(22 \%)$ based on FRAX ${ }^{\circledR}$ score (WHO, University of Sheffield, UK), vertebral fractures were decreased by $50 \%$ and all fractures by $33 \% .{ }^{58}$ Bazedoxifene is in the later stages of the approval process at the US FDA for treatment of osteoporosis pending a request for additional safety information in 2008 from an FDA Advisory Committee. It was approved by the European Medicines Agency in April 2009.

Bazedoxifene is also being investigated for use in combination with conjugated estrogen as a "tissue selective estrogen complex (TSEC)" with the rationale that it will block estrogen stimulation of endometrial and breast tissue without the need for progestin therapy, while having an additive effect with estrogen on bone. ${ }^{59}$ Results from a recent study of bazedoxifene-based TSECs showed the combination drug was associated with significantly greater increases in BMD at both spine and hip and significantly greater decreases in markers of bone turnover compared with raloxifene at most doses. ${ }^{58}$

Problems with side effects and demonstrating efficacy in reducing fractures has prevented other SERMS, such as tibilone ${ }^{59}$ and arzoxifene, ${ }^{60}$ from continuing toward approval. A number of other SERMs continue to be developed and await completion of testing in clinical trials. ${ }^{61,62}$

\section{Calcitonin}

Calcitonin is another antiresorptive agent approved for treatment of osteoporosis. Like the endogenous form of the hormone, it acts on the calcitonin receptor on osteoclasts to decrease their activity. Of the many synthetic or recombinant calcitonins from different species that have been used for medical purposes, including human calcitonin, porcine calcitonin, eel calcitonin-derivative, and salmon calcitonin, the salmon preparation (SCT) is the most widely used in clinical practice. ${ }^{63}$

SCT is available as an injectable formulation for intravenous, intramuscular or subcutaneous use, and as a nasal spray. Injectable SCT was the first to be introduced and was approved in the US in 1984 and is available in 90 other countries for osteoporosis treatment. ${ }^{63} \mathrm{SCT}$ was approved as a nasal spray for treatment of postmenopausal osteoporosis in the US in 1995 and is currently the most commonly used calcitonin formulation, in part due to its convenience of administration. ${ }^{63}$ Clinical trials of SCT nasal spray, taken at a dose of $200 \mathrm{IU} /$ day, have demonstrated a $20 \%$ decrease in biomarkers of osteoporosis, a small effect on BMD in the spine (1\%-2\% increase) ${ }^{64-66}$ but a $36 \%$ reduced incidence of vertebral fractures in women with pre-existing vertebral fractures. ${ }^{65}$ No consistent effect on nonvertebral or hip fractures has been demonstrated. An oral SCT preparation is currently in development for clinical use. ${ }^{63}$

\section{Anabolic agents PTH}

A PTH analog is the only anabolic agent currently approved for treatment of osteoporosis in the US where it is available in the form of human recombinant PTH peptide 1-34 (teriparatide), a fragment of PTH that has a similar affinity for PTH receptor-1. An additional form, rhPTH1-84, which is identical to the endogenous full length PTH in humans, is currently available in Europe.

Although physiologically PTH is released in response to low serum calcium and acts to mobilize calcium from the bone, pharmacologically, when given intermittently 
at low doses, it has been shown to have predominantly anabolic effects on osteoblasts. As indicated by markers of bone turnover, PTH initiates bone formation first and only later promotes bone resorption, resulting in an "anabolic window" of approximately 18-24 months in duration. ${ }^{67}$

The recommended dose of teriparatide is $20 \mu \mathrm{g} /$ day; given as a subcutaneous injection with a modified insulinpen. In clinical trials overall, teriparatide was shown to: increase BMD at both the spine, up to $10 \%$, and femur, to a lesser degree; and decrease vertebral fractures by about $65 \%$ and nonvertebral fractures by about 35\%. ${ }^{68,69}$ Because its effects on BMD have not been consistent across trials, teriparatide is only approved for osteoporosis treatment and not prevention. Because the long-term safety and efficacy are not known, PTH can be prescribed for no more than 24 months. It is contraindicated in patients with hyperparathyroidism, hypercalcemia, or at risk of osteosarcoma, including those with unexplained high alkaline phosphatase levels, Paget's disease, or who have undergone irradiation on the bones. ${ }^{67}$

\section{Strontium ranelate}

Strontium ranelate is an oral agent that has been approved for use in osteoporosis treatment in European countries since 2004. It is not approved in the US, but a related compound, strontium malonate, has FDA investigational new drug status. Strontium ranelate consists of two atoms of strontium and an organic moiety (ranelic acid) which dissociates in the digestive tract. Like calcium, strontium is a cation that is incorporated into the crystal structure of bone.

Strontium ranelate acts by both stimulating bone formation and decreasing bone resorption. In vitro, strontium ranelate has been shown to increase osteoblastic activity, including increasing collagen synthesis and modulating the OPG/RANKL system in favor of OPG, as well as decrease bone resorption by decreasing osteoclast differentiation and resorbing activity, and increasing osteoclast apoptosis. ${ }^{70}$ However, in vivo, some evidence suggests bone formation is favored with nonsignificant effects on bone resorption. ${ }^{71}$

In a summary of the results of four clinical trials of strontium ranelate, three for treatment of osteoporosis ${ }^{72-74}$ and one for prevention, ${ }^{75} 2 \mathrm{~g}$ /day of strontium ranelate resulted in increased BMD at all sites, a 37\% reduction in vertebral fractures and a $14 \%$ reduction in nonvertebral fractures over three years. ${ }^{71}$ As a result, the treatment received a "silver level of evidence" for reducing vertebral, and to a lesser degree nonvertebral, fractures in postmenopausal women from the Cochrane Collaboration. ${ }^{71}$ More recently, a five-year follow-up of one of the treatment trials demonstrated a $43 \%$ reduction in hip fractures and $24 \%$ reduction in vertebral fractures. ${ }^{76}$

\section{New agents New PTH analogs}

Ostabolin-C is a cyclic 31-amino acid analog of PTH that activates the same PTH1 Type receptor activated by the other currently available PTH analogs. ${ }^{77}$ Unlike the current PTH analogs, however, ostabolin-C stimulates adenylyl cyclase alone and not in combination phospholipase $\mathrm{C}$. These modifications are expected to limit its side effects. ${ }^{78}$ In a Phase II trial, daily subcutaneous injections of ostabolin-C in postmenopausal women with osteoporosis resulted in an increase in spine BMD of up to $5 \%$ after four months as reported by the drug's manufacturer. ${ }^{79}$ Episodes of hypercalcemia were more frequent than in the placebo group only at the highest doses. Phase III trials of the injectable medication are now ongoing and a nasal spray preparation is under development. ${ }^{79}$

\section{New agents with new targets}

Denosumab is a human monoclonal antibody that binds to RANKL, the principal mediator of osteoclastic bone resorption (Figure 2). By inhibiting the action of RANKL, denosumab causes a reduction in the differentiation, activity, and survival of osteoclasts, leading to lower rates of bone resorption. ${ }^{80}$ It is given subcutaneously at a dose of $60 \mathrm{mg}$ every six months. Denosumab has been proposed to have several advantages over bisphosphonate therapy, including the potential for increased compliance due to less frequent and easier administration (subcutaneous injection vs intravenous for zoledronic acid) with potentially fewer side effects. ${ }^{81}$

In the recently reported Phase III FREEDOM (Fracture Reduction Evaluation of Denosumab in Osteoporosis every six Months) trial of 7,868 women ages of 60-90 years with T-scores of -4.0 to -2.5 at the lumbar spine or total hip, subjects receiving denosumab had a significant reduction in vertebral fracture of $68 \%$, in hip fracture of $40 \%$, and in other nonvertebral fracture of $20 \%$ compared to those receiving placebo after three years. ${ }^{82}$

In August 2009, the drug received FDA fast-track status for treatment of osteoporosis. Final approval was delayed in October 2009, pending additional information on the proposed post-marketing surveillance program and updated safety data. The information was provided in January 2010 and approval 


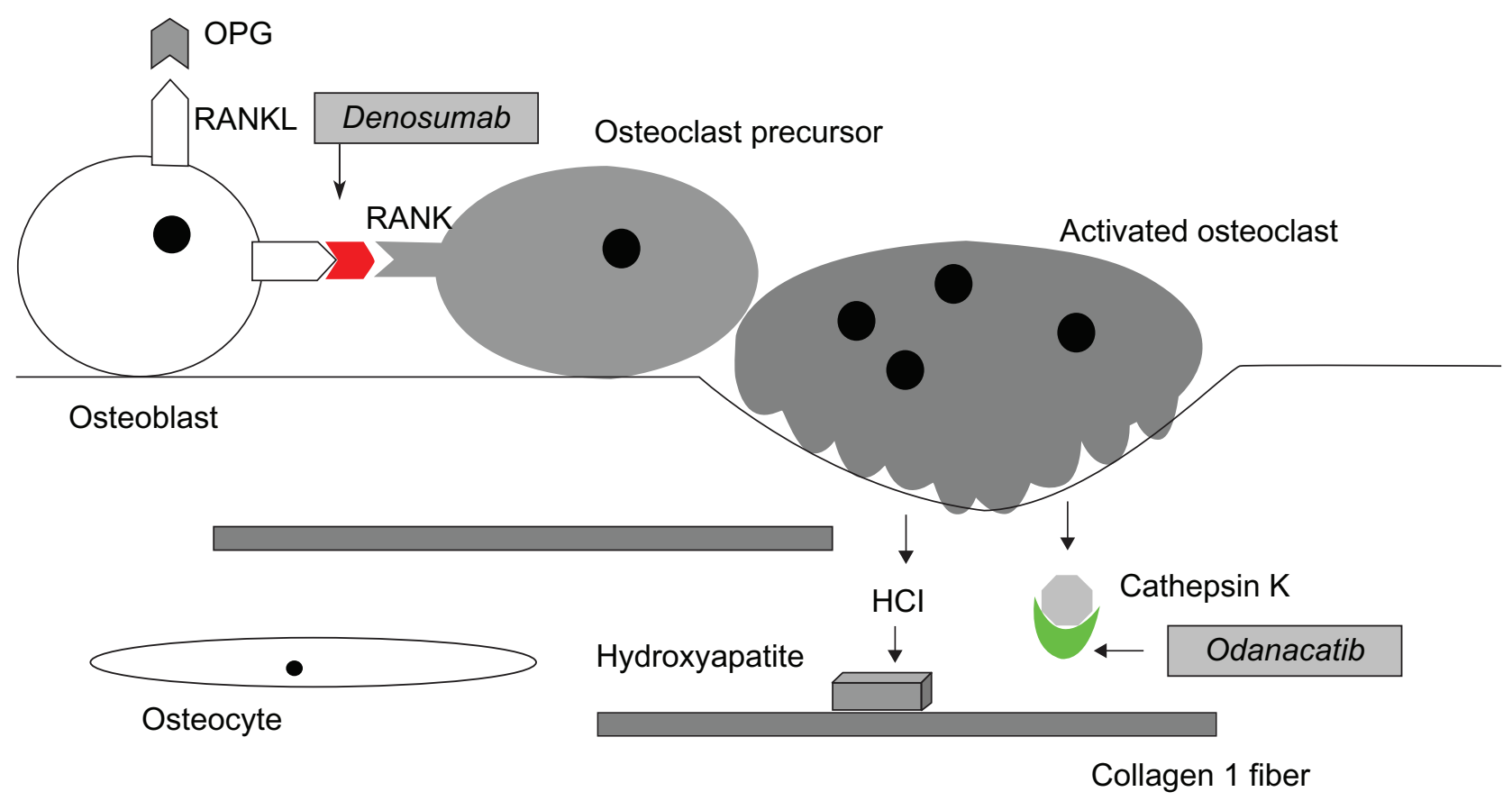

Figure $2 \mathrm{New}$ drug targets in RANK/RANKL/Osteoprotegerin signaling system. Odanacatib is an inhibitor of cathepsin K that prevents the osteoclast-secreted enzyme from breaking down collagen and other components of the bone matrix. Denosumab is a monoclonal antibody that targets the RANKL molecule, preventing its activation of the RANK receptor molecule on osteoclasts.

is expected in July $2010 .{ }^{83}$ Denosumab received a positive opinion from the European Medicines Agency in December 2009, with final approval also expected in $2010 .{ }^{84}$

Odanacatib is an orally administered inhibitor of cathepsin $\mathrm{K}$ being developed for treatment of osteoporosis and bone metastases. As described above, cathepsin $\mathrm{K}$ is the major collagenase secreted by osteoclasts to degrade the organic bone matrix during the bone remodeling process (Figure 2). In a recently reported Phase II clinical trial in postmenopausal women with osteoporosis, 24 months of treatment with odanacatib $50 \mathrm{mg} /$ week produced increases in BMD of $5.5 \%$ at the spine and $3.2 \%$ at the hip. ${ }^{85}$ Side effects appeared to be minimal, in contrast to earlier trials of another cathepsin $\mathrm{K}$ inhibitor that had been associated with skin problems including sclerosis. ${ }^{86}$ Phase III trials of odanacatib that will involve up to 20,000 women are ongoing.

\section{Emerging therapies}

New discoveries related to pathways regulating osteoblast and osteoclast function are leading to the development an increasing number of osteoporosis drugs with novel targets. The Wnt/ $\beta$-catenin pathway that regulates gene transcription of proteins important for osteoblast function is one such target (Figure 3). Wnt signaling is activated by one of 19 secreted Wnt proteins binding to one of 10 frizzled receptors, initiating a signaling cascade which results in the release of $\beta$-catenin from a complex containing glycogen synthase kinase $3 \beta$ (GSK3 $\beta$ ), and its subsequent accumulation and translocation into the nucleus. $\beta$-catenin then binds with the transcription factor tcf/lef and initiates target gene transcription that leads to increased bone formation. ${ }^{87}$

The first clues of the importance of the pathway in bone regulation were studies showing specific mutations of the gene for a Wnt receptor, lipoprotein receptor-like protein 5 (LRP5), were involved in syndromes of osteoporosis (osteoporosis pseudoglioma); other mutations of the same gene were subsequently associated with high bone mass. LRP5 is a co-receptor along with the frizzled receptors for Wnt proteins. Study of the pathway has led to further discovery of inhibitors of Wnt signaling secreted by osteocytes. These include sclerostin and dickkopf 1 protein (DKK1), both of which block binding of Wnt to LRP5 (or the related LRP6 receptor), thereby inhibiting osteoblast stimulation. Sclerostin is the protein product of the SOST gene, mutations of which cause sclerosing bone diseases. ${ }^{88,89}$ Decreased sclerostin secretion has been implicated as the signal for increasing Wnt pathway activity in mechanical stimulation of bone. ${ }^{90}$

Monoclonal antibodies designed to block the inhibiting action of both sclerostin and DKK1 are being considered for clinical trials based on promising results in animal 


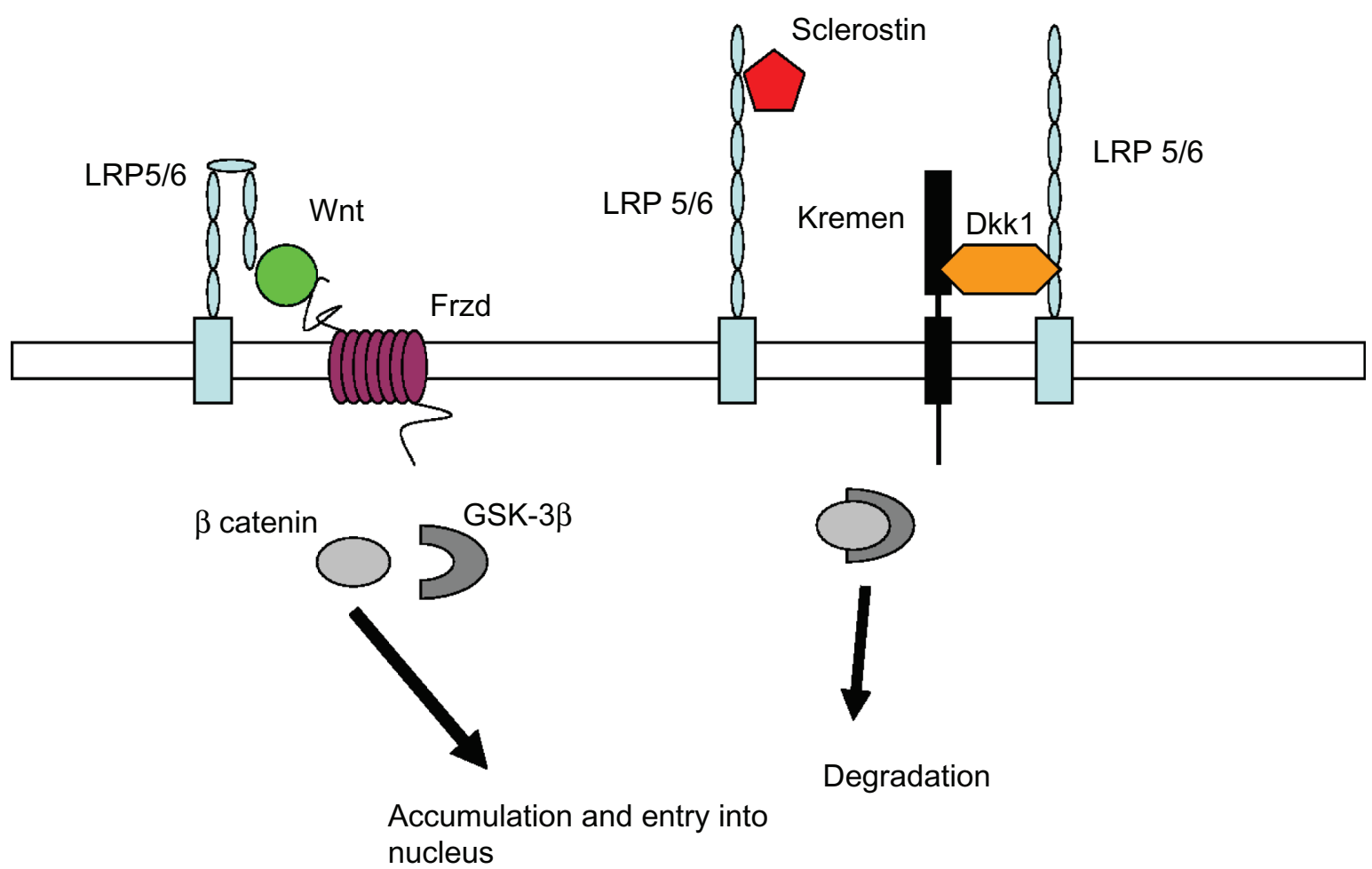

Figure $3 \mathrm{Wnt} / \mathrm{\beta}$-catenin pathway in osteoblasts. Binding of the Wnt molecule to co-receptors on the osteoblast-lipoprotein-related protein (LRP $5 / 6)$ and Frizzled (Frzd) - activates release of $\beta$-catenin within the cell from a complex containing glycogen serine kinase (GSK-3 $\beta$ ), resulting in accumulation of $\beta$-catenin and translocation into the nucleus where it regulates gene expression. Sclerostin (Sost) and dickkopf (DKK-I) are two proteins that inhibit LRP $5 / 6$ from activating this pathway, resulting in degradation of $\beta$-catenin by GSK-3 $\beta$. Antibodies to both sclerostin and DKK-I are currently under development as potential anabolic (osteoblast-stimulating) osteoporosis therapies. (Graphic adapted from Hoeppner et $\mathrm{al}^{95}$ and Gallagher and Sai. ${ }^{98}$ )

models..$^{91-93}$ Because both of these molecules appear to be secreted only by bone, it is hoped that they will have fewer systemic adverse effects than other Wnt pathway-related therapies. Therapies targeted at other molecules in the pathway, for example a small molecule inhibitor of GSK $3 \beta,{ }^{94}$ the enzyme which causes degradation of $\beta$-catenin in the absence of Wnt signaling, are considered less desirable targets due to their action in many tissues in addition to bone. ${ }^{95}$

Therapies being developed based on other targets include calcium receptor antagonists that stimulate transient release of PTH from the parathyroid gland.${ }^{96}$ Bone morphogenetic proteins, growth factors belonging to TGF- $\beta$ superfamily and involved in a multitude of processes including embryonic and post natal development, are potent bone inducers being used in clinical studies for local fracture healing. Their potential for treatment in osteoporosis is also being explored. ${ }^{97}$

\section{Conclusion}

Many new agents for osteoporosis therapy are currently in the development pipeline. Several of these agents, including denosumab, a monoclonal antibody that blocks the actions of the collagenase cathepsin K, are nearing US FDA approval.
Further elucidation of the role of Wnt signaling and other pathways in osteoblasts promises to add more treatment options in the coming decade, with a greater emphasis on anabolic agents. These agents may also be useful in combination with existing antiresorptive agents, further expanding therapeutic options in the future.

\section{Acknowledgment}

This is manuscript 20746-MEM. The work was supported by a grant from the National Institutes of Health AR054901$01 \mathrm{~A} 2$.

\section{Disclosure}

The author reports no conflicts of interest in this work.

\section{References}

1. Curtis JR, McClure LA, Delzell E, et al. Population-based fracture risk assessment and osteoporosis treatment disparities by race and gender. J Gen Intern Med. 2009;24:956-962.

2. McClung MR. The relationship between bone mineral density and fracture risk. Curr Osteoporos Rep. 2005;3:57-63.

3. World Health Organization. Assessment of fracture risk and its application to screening for postmenopausal osteoporosis. Report of a WHO Study Group. World Health Organ Tech Rep Ser. 1994;843:1-129. 
4. International Osteoporosis Foundation. Facts and statistics about osteoporosis and its impact. 2009. Available from: http://www.iofbonehealth.org/facts-and-statistics.html. Accessed Apr 7, 2010.

5. National Osteoporosis Foundation. Fast facts on osteoporosis. 2008. Available from: http://www.nof.org/osteoporosis/diseasefacts.htm. Accessed Apr 7, 2010.

6. Kanis JA, McCloskey EV, Johansson H, Strom O, Borgstrom F, Oden A. How to decide who to treat. Best Pract Res Clin Rheumatol. 2009;23:711-726.

7. Lim LS, Hoeksema LJ, Sherin K. Screening for osteoporosis in the adult US population: ACPM position statement on preventive practice. Am J Prev Med. 2009;36:366-375.

8. World Health Organization. FRAX ${ }^{\circledR}$ WHO fracture risk assessment tool. 2008. Available from: http://www.sheffield.ac.uk/FRAX/. Accessed Apr 7, 2010

9. National Osteoporosis Foundation. 2008. Clinician's guide to prevention and treatment of osteoporosis. Available from: http://www.nof.org/ professionals/pdfs/NOF_ClinicianGuide2009_v7.pdf. Accessed Apr 7, 2010.

10. Seeman E, Compston J, Adachi J, et al. Non-compliance: the Achilles' heel of anti-fracture efficacy. Osteoporos Int. 2007;18:711-719.

11. Cawston TE, Young DA. Proteinases involved in matrix turnover during cartilage and bone breakdown. Cell Tissue Res. 2010;339:221-235.

12. Sommerfeldt DW, Rubin CT. Biology of bone and how it orchestrates the form and function of the skeleton. Eur Spine J. 2001; 10 Suppl 2:S86-S95.

13. Ahlborg HG, Johnell O, Nilsson BE, Jeppsson S, Rannevik G, Karlsson MK. Bone loss in relation to menopause: a prospective study during 16 years. Bone. 2001;28:327-331.

14. Christakos S, Dhawan P, Shen Q, Peng X, Benn B, Zhong Y. New insights into the mechanisms involved in the pleiotropic actions of 1,25 dihydroxyvitamin D3. Ann NY Acad Sci. 2006;1068:194-203.

15. De Paula FJ, Rosen CJ. Back to the future: revisiting parathyroid hormone and calcitonin control of bone remodeling. Horm Metab Res. 2010;42:299-306

16. Nakamura T, Imai Y, Matsumoto T, et al. Estrogen prevents bone loss via estrogen receptor alpha and induction of Fas ligand in osteoclasts. Cell. 2007;130:811-823.

17. Krum SA, Miranda-Carboni GA, Hauschka PV, et al. Estrogen protects bone by inducing Fas ligand in osteoblasts to regulate osteoclast survival. EMBO J. 2008;27:535-545.

18. Wright HL, McCarthy HS, Middleton J, Marshall MJ. RANK, RANKL, and osteoprotegerin in bone biology and disease. Curr Rev Musculoskelet Med. 2009;2:56-64.

19. Lewiecki EM. Monitoring pharmacological therapy for osteoporosis. Rev Endocr Metab Disord. 2010; Feb 9. [Epub ahead of print].

20. National Osteoporosis Foundation. Updated recommendations for calcium and vitamin D intake. Oct, 2008. Available from: http:/www.nof. org/prevention/calcium_and_VitaminD.htm. Accessed Apr 7, 2010.

21. Ginde AA, Liu MC, Camargo CA Jr. Demographic differences and trends of vitamin D insufficiency in the US population, 1988-2004. Arch Intern Med. 2009;169:626-632.

22. DeLuca HF. Overview of general physiologic features and functions of vitamin D. Am J Clin Nutr. 2004;80 Suppl 6:1689S-1696S.

23. Lips P. Worldwide status of vitamin D nutrition. J Steroid Biochem Mol Biol. 2010;121(1-2):297-300.

24. National Institutes of Health, Office of Dietary Supplements. Dietary supplement fact sheet: vitamin D. Nov 13, 2009. Available from: http:// ods.od.nih.gov/factsheets/vitamind.asp. Accessed May 19, 2010.

25. Adams JS, Hewison M. Update in vitamin D. J Clin Endocrinol Metab. 2010;95:471-478.

26. American College of Sports Medicine. Exercise and osteoporosis. 2007. Available from: http://www.acsm.org/AM/Template. $\mathrm{cfm}$ ?Section=Home_Page $\&$ Template $=/ \mathrm{CM} /$ HTMLDisplay. cfm\&ContentID=8170. Accessed May 19, 2010.
27. National Osteoporosis Foundation. Exercise for healthy bones. 2008. Available from: http://www.nof.org/prevention/exercise.htm. Accessed May 19, 2010

28. Fitzpatrick LA. Secondary causes of osteoporosis. Mayo Clin Proc. 2002;77:453-468.

29. Hanley DA, Ioannidis G, Adachi JD. Etridronate therapy in the treatment and prevention of osteoporosis. J Clin Densitom . 2000;3:79-95.

30. Frediani B, Cavalieri L, Cremonesi G. Clodronic acid formulations available in Europe and their use in osteoporosis: a review. Clin Drug Investig. 2009;29:359-379.

31. Drake MT, Clarke BL, Khosla S. Bisphosphonates: mechanism of action and role in clinical practice. Mayo Clin Proc. 2008;83:1032-1045.

32. Watts NB, Diab DL. Long-term use of bisphosphonates in osteoporosis. J Clin Endocrinol Metab. 2010;95:1555-1565.

33. Russell RG, Watts NB, Ebetino FH, Rogers MJ. Mechanisms of action of bisphosphonates: similarities and differences and their potential influence on clinical efficacy. Osteoporos Int. 2008;19:733-759.

34. Khosla S, Burr D, Cauley J, et al. Bisphosphonate-associated osteonecrosis of the jaw: report of a task force of the American Society for Bone and Mineral Research. J Bone Miner Res. 2007;22: 1479-1491.

35. Black DM, Kelly MP, Genant HK, et al. Bisphosphonates and fractures of the subtrochanteric or diaphyseal femur. $N$ Engl J Med. 2010;362:1761-1771

36. National Institutes of Health. Osteoporosis. NIH consensus development conference statement. Natl Inst Health Consens Dev Conf Consens Statement. 1984;5(3):6 p.

37. Hersh AL, Stefanick ML, Stafford RS. National use of postmenopausal hormone therapy: annual trends and response to recent evidence. JAMA. 2004;291:47-53.

38. Haas JS, Kaplan CP, Gerstenberger EP, Kerlikowske K. Changes in the use of postmenopausal hormone therapy after the publication of clinical trial results. Ann Intern Med. 2004;140:184-188.

39. Barbaglia G, Macia F, Comas M, et al. Trends in hormone therapy use before and after publication of the Women's Health Initiative trial: 10 years of follow-up. Menopause. 2009;16:1061-1064.

40. Faber A, Bouvy ML, Loskamp L, van de Berg PB, Egberts TC, de Jong-van den Berg LT. Dramatic change in prescribing of hormone replacement therapy in The Netherlands after publication of the Million Women Study: a follow-up study. Br J Clin Pharmacol. 2005;60: 641-647.

41. Huot L, Couris CM, Tainturier V, Jaglal S, Colin C, Schott AM. Trends in HRT and anti-osteoporosis medication prescribing in a European population after the WHI study. Osteoporos Int. 2008;19:1047-1054.

42. Martin RM, Wheeler BW, Metcalfe C, Gunnell D. What was the immediate impact on population health of the recent fall in hormone replacement therapy prescribing in England? Ecological study. J Public Health (Oxf). 2010; Mar 28. [Epub ahead of print].

43. Rossouw JE, Anderson GL, Prentice RL, et al. Risks and benefits of estrogen plus progestin in healthy postmenopausal women: principal results from the Women's Health Initiative randomized controlled trial. JAMA. 2002;288:321-333.

44. Anderson GL, Limacher M, Assaf AR, et al. Effects of conjugated equine estrogen in postmenopausal women with hysterectomy: the Women's Health Initiative randomized controlled trial. JAMA. 2004;291:1701-1712.

45. Stefanick ML. Estrogens and progestins: background and history, trends in use, and guidelines and regimens approved by the US Food and Drug Administration. Am J Med. 2005;19(118 Suppl 12):64-73.

46. Goldstein SR, Duvernoy CS, Calaf J, et al. Raloxifene use in clinical practice: efficacy and safety. Menopause. 2009;16:413-421.

47. Delmas PD, Bjarnason NH, Mitlak BH, et al. Effects of raloxifene on bone mineral density, serum cholesterol concentrations, and uterine endometrium in postmenopausal women. N Engl J Med. 1997;337: $1641-1647$ 
48. Johnston CC Jr, Bjarnason NH, Cohen FJ, et al. Long-term effects of raloxifene on bone mineral density, bone turnover, and serum lipid levels in early postmenopausal women: three-year data from 2 double-blind, randomized, placebo-controlled trials. Arch Intern Med. 2000;160:3444-3450.

49. Ettinger B, Black DM, Mitlak BH, et al. Reduction of vertebral fracture risk in postmenopausal women with osteoporosis treated with raloxifene: results from a 3-year randomized clinical trial. Multiple Outcomes of Raloxifene Evaluation (MORE) Investigators. JAMA. 1999;282:637-645.

50. Martino S, Cauley JA, Barrett-Connor E, et al. Continuing outcomes relevant to Evista: breast cancer incidence in postmenopausal osteoporotic women in a randomized trial of raloxifene. J Natl Cancer Inst. 2004;96:1751-1761.

51. Gennari L, Merlotti D, Nuti R. Selective estrogen receptor modulator (SERM) for the treatment of osteoporosis in postmenopausal women: focus on lasofoxifene. Clin Interv Aging. 2010;5:19-29.

52. Lewiecki EM. Lasofoxifene for the prevention and treatment of postmenopausal osteoporosis. Ther Clin Risk Manag. 2009;5: 817-827.

53. Gennari L, Merlotti D, Valleggi F, Martini G, Nuti R. Selective estrogen receptor modulators for postmenopausal osteoporosis: current state of development. Drugs Aging. 2007;24:361-379.

54. Cummings SR, Ensrud K, Delmas PD, et al. Lasofoxifene in postmenopausal women with osteoporosis. $N$ Engl J Med. 2010;362 686-696.

55. Gennari L, Merlotti D, De Paola V, Martini G, Nuti R. Bazedoxifene for the prevention of postmenopausal osteoporosis. Ther Clin Risk Manag. 2008;4:1229-1242.

56. Miller PD, Chines AA, Christiansen C, et al. Effects of bazedoxifene on BMD and bone turnover in postmenopausal women: 2-yr results of a randomized, double-blind, placebo-, and active-controlled study. J Bone Miner Res. 2008;23:525-535.

57. Kanis JA, Johansson H, Oden A, McCloskey EV. Bazedoxifene reduces vertebral and clinical fractures in postmenopausal women at high risk assessed with FRAX. Bone. 2009;44:1049-1054.

58. Lindsay R, Gallagher JC, Kagan R, Pickar JH, Constantine G. Efficacy of tissue-selective estrogen complex of bazedoxifene/conjugated estrogens for osteoporosis prevention in at-risk postmenopausal women. Fertil Steril. 2009;92:1045-1052.

59. Cummings SR, Ettinger B, Delmas PD, et al. The effects of tibolone in older postmenopausal women. $N$ Engl J Med. 2008;359:697-708.

60. De Paula FJ, Rosen CJ. Developing drugs to treat osteoporosis: lessons learned? Expert Opin Pharmacother. 2010;11:867-869.

61. Shelly W, Draper MW, Krishnan V, Wong M, Jaffe RB. Selective estrogen receptor modulators: an update on recent clinical findings. Obstet Gynecol Surv. 2008;63:163-181.

62. Vogelvang TE, van der Mooren MJ, Mijatovic V, Kenemans P. Emerging selective estrogen receptor modulators: special focus on effects on coronary heart disease in postmenopausal women. Drugs. 2006;66:191-221

63. Chesnut CH III, Azria M, Silverman S, Engelhardt M, Olson M, Mindeholm L. Salmon calcitonin: a review of current and future therapeutic indications. Osteoporos Int. 2008;19:479-491.

64. Overgaard K. Effect of intranasal salmon calcitonin therapy on bone mass and bone turnover in early postmenopausal women: a dose-response study. Calcif Tissue Int. 1994;55:82-86.

65. Chesnut CH III, Silverman S, Andriano K, et al. A randomized trial of nasal spray salmon calcitonin in postmenopausal women with established osteoporosis: the prevent recurrence of osteoporotic fractures study. PROOF Study Group. Am J Med. 2000;109:267-276.

66. Chesnut CH III, Majumdar S, Newitt DC, et al. Effects of salmon calcitonin on trabecular microarchitecture as determined by magnetic resonance imaging: results from the QUEST study. J Bone Miner Res. 2005;20:1548-1561.
67. Pleiner-Duxneuner J, Zwettler E, Paschalis E, Roschger P, Nell-Duxneuner V, Klaushofer K. Treatment of osteoporosis with parathyroid hormone and teriparatide. Calcif Tissue Int. 2009;84: $159-170$.

68. Trevisani VF, Riera R, Imoto AM, Saconato H, Atallah AN. Teriparatide (recombinant human parathyroid hormone 1-34) in postmenopausal women with osteoporosis: systematic review. Sao Paulo Med J. 2008; 126:279-284.

69. Vestergaard P, Jorgensen NR, Mosekilde L, Schwarz P. Effects of parathyroid hormone alone or in combination with anti-resorptive therapy on bone mineral density and fracture risk - a meta-analysis. Osteoporos Int. 2007;18:45-57.

70. Neuprez A, Hiligsmann M, Scholtissen S, Bruyere O, Reginster JY. Strontium ranelate: the first agent of a new therapeutic class in osteoporosis. Adv Ther. 2008;25:1235-1256.

71. O’Donnell S, Cranney A, Wells GA, Adachi JD, Reginster JY. Strontium ranelate for preventing and treating postmenopausal osteoporosis. Cochrane Database Syst Rev. 2006;3:CD005326.

72. Meunier PJ, Slosman DO, Delmas PD, et al. Strontium ranelate: dose-dependent effects in established postmenopausal vertebral osteoporosis - a 2-year randomized placebo controlled trial. J Clin Endocrinol Metab. 2002;87:2060-2066.

73. Meunier PJ, Roux C, Seeman E, et al. The effects of strontium ranelate on the risk of vertebral fracture in women with postmenopausal osteoporosis. N Engl J Med. 2004;350:459-468.

74. Reginster JY, Seeman E, De Vernejoul MC, et al. Strontium ranelate reduces the risk of non-vertebral fractures in postmenopausal women with osteoporosis: Treatment of Peripheral Osteoporosis (TROPOS) study. J Clin Endocrinol Metab. 2005;90:2816-2822.

75. Reginster JY, Deroisy R, Dougados M, Jupsin I, Colette J, Roux C. Prevention of early postmenopausal bone loss by strontium ranelate: the randomized, two-year, double-masked, dose-ranging, placebo-controlled PREVOS trial. Osteoporos Int. 2002;13:925-931.

76. Reginster JY, Felsenberg D, Boonen S, et al. Effects of long-term strontium ranelate treatment on the risk of non-vertebral and vertebral fractures in postmenopausal osteoporosis: results of a five-year, randomized, placebo-controlled trial. Arthritis Rheum. 2008;58: $1687-1695$

77. Nemeth EF. ZT-031, a cyclized analog of parathyroid hormone (1-31) for the potential treatment of osteoporosis. IDrugs. 2008;11:827-840.

78. Whitfield JF, Morley P, Willick G, et al. Cyclization by a specific lactam increases the ability of human parathyroid hormone (hPTH)-(1-31) $\mathrm{NH} 2$ to stimulate bone growth in ovariectomized rats. $J$ Bone Miner Res. 1997; 12:1246-1252.

79. Zelos. Zelos Therapeutics' Ostabolin-C $\mathrm{C}^{\mathrm{TM}}$ increases bone mineral density in phase 2 osteoporosis trial. 2010. Available from: http://www. zelostherapeutics.com/news/020807.htm. Accessed Jun 6, 2010.

80. Lewiecki EM. Treatment of osteoporosis with denosumab. Maturitas. 2010;66:182-186.

81. Schwarz EM, Ritchlin CT. Clinical development of anti-RANKL therapy. Arthritis Res Ther. 2007;9 Suppl 1:S7.

82. Cummings SR, San MJ, McClung MR, et al. Denosumab for prevention of fractures in postmenopausal women with osteoporosis. $\mathrm{N} \mathrm{Engl}$ J Med. 2009;361:756-765.

83. Amgen, Inc. FDA classifies prolia ${ }^{\mathrm{TM}}$ (denosumab) complete response submission and targets action date. Feb, 2010. Available from: http://finance.yahoo.com/news/FDA-Classifies-ProliaTM-prnews2110666215.html?x=0\&.v=1. Accessed April 7, 2010.

84. Amgen, Inc. Amgen receives CHMP positive opinion for prolia ${ }^{\mathrm{TM}}$ (denosumab) in the European Union. Dec 18, 2009. Available from: http://www.amgen.com/media/media_pr_detail.jsp?year=2009\&relea seID=1367560. Accessed Apr 15, 2010.

85. Bone HG, McClung MR, Roux $\mathrm{C}$, et al. Odanacatib, a cathepsin-K inhibitor for osteoporosis: a two-year study in postmenopausal women with low bone density. J Bone Miner Res. 2010;25(5):937-947. 
86. Peroni A, Zini A, Braga V, Colato C, Adami S, Girolomoni G. Drug-induced morphea: report of a case induced by balicatib and review of the literature. J Am Acad Dermatol. 2008;59:125-129.

87. Baron R, Rawadi G. Targeting the Wnt/beta-catenin pathway to regulate bone formation in the adult skeleton. Endocrinology. 2007; 148:2635-2643.

88. Balemans W, Ebeling M, Patel N, et al. Increased bone density in sclerosteosis is due to the deficiency of a novel secreted protein (SOST). Hum Mol Genet. 2001;10:537-543.

89. Balemans W, Patel N, Ebeling M, et al. Identification of a $52 \mathrm{~kb}$ deletion downstream of the SOST gene in patients with van Buchem disease. J Med Genet. 2002;39:91-97.

90. Robling AG, Niziolek PJ, Baldridge LA, et al. Mechanical stimulation of bone in vivo reduces osteocyte expression of SOST/sclerostin. J Biol Chem. 2008;283:5866-5875.

91. Li X, Ominsky MS, Warmington KS, et al. Sclerostin antibody treatment increases bone formation, bone mass, and bone strength in a rat model of postmenopausal osteoporosis. J Bone Miner Res. 2009;24:578-588.

92. Betts AM, Clark TH, Yang J, et al. The application of target information and preclinical pharmacokinetic/pharmacodynamic modeling in predicting clinical doses of a dickkopf-1 antibody for osteoporosis. J Pharmacol Exp Ther. 2010;333:2-13.
93. Ominsky MS, Vlasseros F, Jolette $\mathrm{J}$, et al. Two doses of sclerostin antibody in cynomolgus monkeys increases bone formation, bone mineral density, and bone strength. J Bone Miner Res. 2010;25(5): 948-959.

94. Kulkarni NH, Onyia JE, Zeng Q, et al. Orally bioavailable GSK-3alpha/ beta dual inhibitor increases markers of cellular differentiation in vitro and bone mass in vivo. J Bone Miner Res. 2006;21:910-920.

95. Hoeppner LH, Secreto FJ, Westendorf JJ. Wnt signaling as a therapeutic target for bone diseases. Expert Opin Ther Targets. 2009;13:485-496.

96. Kumar S, Matheny CJ, Hoffman SJ, et al. An orally active calciumsensing receptor antagonist that transiently increases plasma concentrations of PTH and stimulates bone formation. Bone. 2010;46: 534-542.

97. Li B. Bone morphogenetic protein-Smad pathway as drug targets for osteoporosis and cancer therapy. Endocr Metab Immune Disord Drug Targets. 2008;8:208-219.

98. Gallagher JC, Sai AJ. Molecular biology of bone remodeling: implications for new therapeutic targets for osteoporosis. Maturitas. 2010;65:301-307.
Journal of Experimental Pharmacology

\section{Publish your work in this journal}

The Journal of Experimental Pharmacology is an international, peerreviewed, open access journal publishing original research, reports, reviews and commentaries on all areas of laboratory and experimental pharmacology. The manuscript management system is completely online and includes a very quick and fair peer-review system.

\section{Dovepress}

Visit http://www.dovepress.com/testimonials.php to read real quotes from published authors. 